Alma Mater Studiorum - Università di Bologna DEPARTMENT OF ECONOMICS

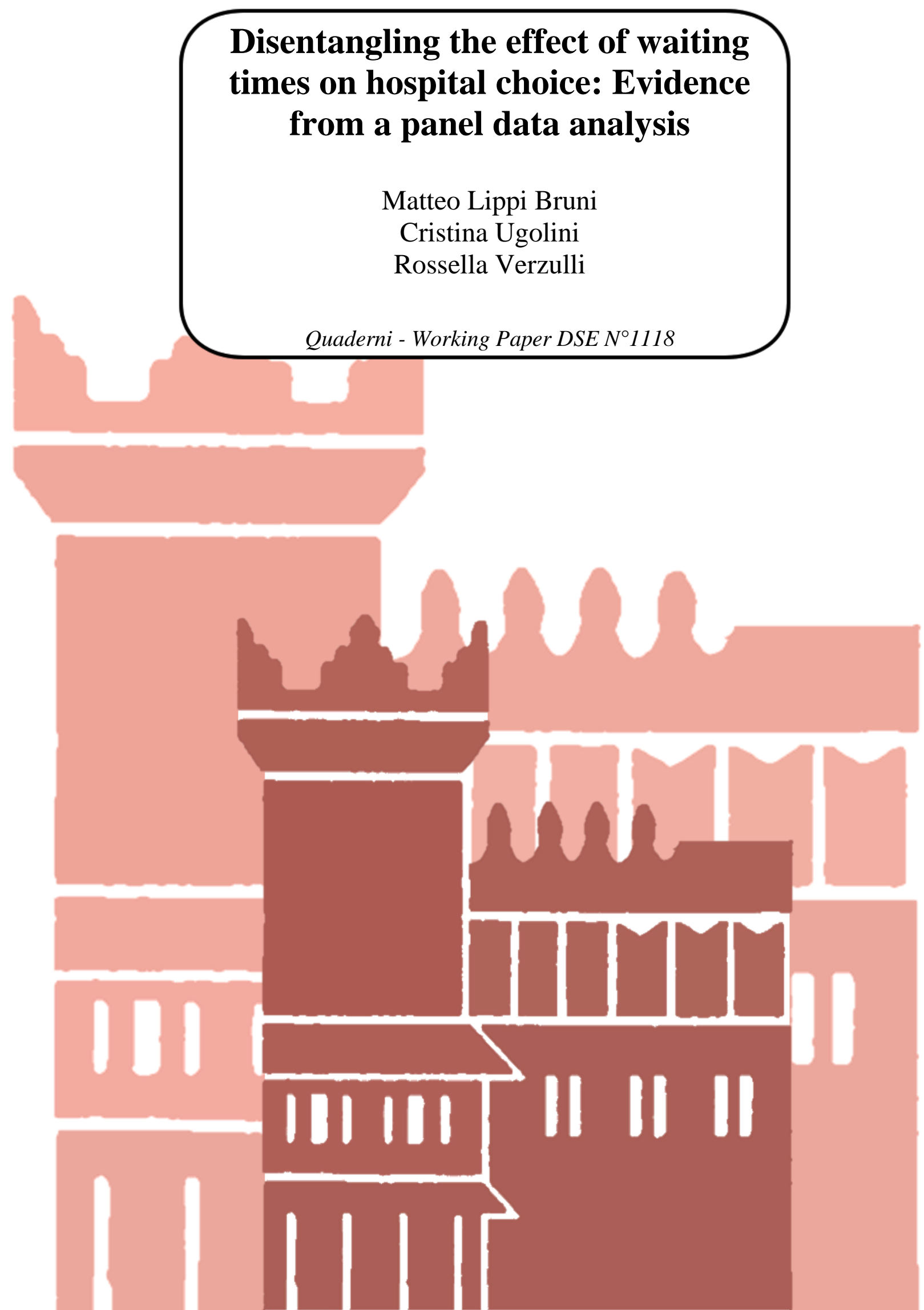




\title{
Disentangling the effect of waiting times on hospital choice: Evidence from a panel data analysis
}

\author{
Matteo Lippi Bruni, Cristina Ugolini, Rossella Verzulli \\ Department of Economics, University of Bologna
}

Piazza Scaravilli 2, 20146 Italy

Corresponding author: Rossella Verzulli, rossella.verzulli@unibo.it

\begin{abstract}
This study examines the effect of waiting times on hospital choice by using patientlevel data on elective Percutaneous Transluminal Coronary Angioplasty (PTCA) procedures in the Italian NHS over the years 2008-2011. We perform a multinomial logit analysis including conditional logit and mixed logit specifications. Our findings show the importance of jointly controlling for time-invariant and time varying dimensions of hospital quality in order to disentangle the effect of waiting times on hospital choice. We provide evidence that patients are responsive to changes in waiting times and aspects of clinical quality within hospitals over time, and estimate the trade-off that patients make between different hospital attributes. The results convey important policy implications for highly regulated health care markets.
\end{abstract}

Key terms: hospital choice, waiting times, hospital quality, multinomial logit models.

JEL codes: I10 


\section{Introduction}

Among the reforms that have characterised hospital care in publicly financed health systems, two waves of initiatives stand out: the effort for shortening waiting times, and the enhancement of patient hospital choice. Faced with binding financial constraints, public authorities have extensively used waiting times as a rationing device (Gravelle and Siciliani, 2008). As a result, long waits for elective care are nowadays a major concern in a number of countries where ensuring a timely response to patients' needs has become a priority in the policy agenda. At the same time, patients' empowerment has fostered their involvement in referral and treatment decisions, including hospital choice for elective procedures. These changes reflect a widespread belief that increasing patients' choice opportunities may improve the quality of treatment and social welfare (Cookson and Dawson, 2012). In particular, under fixed-price regulation, hospital choice may act as a spur for public organisations to deliver services that match patient preferences and encourages high quality of care (Vrangbaek et al, 2007).

However, there are also reasons for scepticism about patients' ability to exercise an active choice of their hospital destination. This is especially true in equity-oriented public health systems where centrally planned policies and balanced funding schemes may limit hospital autonomy and competition. Moreover, extensive regulation of quality standards may level out the major differences across hospitals, leaving little incentive to bypass the nearest provider. Ultimately, it is an empirical matter to determine whether hospital choice decisions are affected by patients' preferences over 
factors other than geographic proximity, and to what extent patients trade-off hospital attributes.

Because of that, the assessment of patients' response to variations in providers' attributes, together with the identification of preference heterogeneity, is a key piece of information for efficiently regulating public health care systems. If patients are responsive to changes in waiting times and clinical quality, then health care organisations are incentivised to provide more timely responses and higher quality care beyond the (minimum) standards set by government regulation. Moreover, identifying which types of patients are less willing to travel for shorter waiting times or better quality helps policy-makers to target those who may be more vulnerable to poor hospital services delivered locally.

In this study, our primary interest is to provide a patient-level analysis of the effect of waiting times on hospital choice in the Italian National Health Service (NHS). Since hospital care is free of charge, waiting times represent the main cost of treatment, along with the distance travelled to the hospital. Moreover, given that patients' mobility outside the hospital catchment area is financed through a prospective payment scheme, hospitals potentially retain some incentives to attract more patients by offering better services. Using data on elective Percutaneous Transluminal Coronary Angioplasty (PTCA) from the Italian region of Emilia-Romagna for the period 2008-2011, we study the extent to which patients react to changes in waiting times within hospitals over time, while accounting for differences in geographic location and hospital quality. To estimate hospital choice models, we employ conditional logit (CL) and mixed logit (ML) specifications. 
Isolating the effect of waiting times on the patient's choice of hospital poses serious empirical challenges because hospitalisations may reflect preferences for quality. When patients respond to changes in quality, hospitals offering greater quality face higher demand pressure, possibly inducing a positive correlation between waiting times and quality of care. Hence, controlling for variations in quality is necessary to ensure unbiased estimates of the effect of interest. A major advantage of this study over previous research (e.g. Sivey, 2012; Beckert et al, 2012; Varkevisser et al, 2012) is that we benefit from both longitudinal data and quality indicators. We exploit the richness of the dataset to jointly control for time-invariant heterogeneity across providers via hospital fixed effects, and for time varying aspects of quality captured by the risk-adjusted indicators recently released by the Italian Ministry of Health (Piano Nazionale Esiti, PNE).

Focusing on PTCA procedures, we consider two widely used outcome indicators, namely mortality and readmission rates for AMI. Even though this piece of information was not made available to the general public in the period covered by our data, it is used in this study as a proxy for clinical quality as perceived by patients before choosing the hospital. Such information can be gathered from the patient's own experience, or from that of the network of patient's relatives and acquaintances, as well as from the advice of specialists and General Practitioners. Similar assumptions are also found in previous studies showing that the patient's choice of hospital is driven by quality even before the public release of data on quality (e.g. Luft et al, 1990; Moscone et al, 2012; Gutacker et al, 2016). 
Our contribution differs from most studies modelling hospital choice also in that it applies to an NHS-type health system where providers are encouraged to co-operate with each other. In this respect, the institutional framework of the Italian NHS, and of Emilia-Romagna in particular, provides an appealing setting for investigating patients responses to waiting times and clinical quality, and the degree to which they trade-off hospital attributes, even when providers operate under weak competitive pressure. Although hospitals enjoy some autonomy in organising their activity, the system is committed to ensure equity, and quality standards are centrally regulated and monitored. ${ }^{1}$ Moreover, the Italian NHS has been characterized by free patient mobility across jurisdictions since its inception, making our setting especially favourable for a clean identification of the role of patient preferences in hospital choice. Reforms increasing patients' choice opportunities make it often hard to separate demand from supply side effects because providers may be incentivised to develop new strategies that improve their attractiveness (Gaynor et al, 2016). On the contrary, the stability of our regulatory framework rules out possible confounding effects due to providers reacting to changes in the competitive environment associated to variations in hospital choice decisions.

Our findings lend support for the use of a ML model over a CL specification, revealing significant preference heterogeneity in relation to both unobserved and observed patient characteristics. From a methodological point of view, we establish

\footnotetext{
${ }^{1}$ Italian regions are empowered to regulate important aspects of their health care systems, leading to different regional models despite the common national framework. Regions like Lombardy have strongly encouraged competition within the public sector as well as between public and accredited private centres (Moscone et al, 2012). In other cases, such as in Emilia-Romagna where this study is focused, policy-makers have favoured cooperation and coordination among providers (Ferré et al, 2014). Such strategy has been pursued through central planning of hospital production capacity designed to ensure a balanced distribution of activity across areas and the promotion of strong integration between hospital and district-level services.
} 
the importance of jointly controlling for time-invariant differences across hospitals and for time varying measures of clinical quality. We show that failing to do so leads to a sizeable downward bias in the estimates of the effect of waiting times on hospital choice. The results from our most preferred specification yields an elasticity of demand with respect to waiting times of -0.186 , with the average patient willing to travel an extra distance of about 1.1 kilometres for a 1 week reduction in waiting times. Our findings also outline that patients are to some degree sensitive to changes in aspects of clinical quality within hospitals over time, holding other factors constant. The estimated elasticity of demand with respect to the mortality rate is 0.905, whereas there is no significant effect associated to changes in readmission rates. We find a mean willingness to travel for a $10 \%$ decrease in the mortality rate of about 3.5 kilometres. Notably, our estimates show that the average patient trade-offs longer waiting times with higher quality, with the mean willingness to wait for a $10 \%$ decrease in the mortality rate being about 22 days. Interestingly, we find that the size of the trade-off among different hospital attributes significantly varies across patient characteristics.

\section{Background}

The Italian NHS is a public sector organisation, funded out of general taxation, and providing uniform, comprehensive care to the entire population. Health services are largely free of charge at the point of use and patients can seek hospital care from any publicly funded providers. Secondary care is mostly supplied by public hospitals, the majority of which is run by Local Health Authorities (Aziende Sanitarie Locali, 
ASLs), public enterprises responsible for the health needs of their catchment population. Patients' flows out of the ASL of reference are compensated using tariffs based on a DRG scheme. The remaining hospitals are public semi-autonomous Trusts (Aziende Ospedaliere, AOs) with greater financial and administrative autonomy, and extensively financed under a prospective payment system. ${ }^{2}$

As patients are free to choose the admitting hospital and are not charged at the point of use, distance, waiting times and quality of care are expected to be key drivers of hospital choice. Waiting times act as a non-explicit cost from the patient perspective, not only because the utility from health care may decline the longer the patient has to wait for treatment (Lindsay and Feigeinbaum, 1984). Waiting per se may generate disutility for several reasons. For instance, because worse health conditions may hinder patient's ability to work and/or to carry out daily activities, and because waiting for care may be associated with more anxiety and stress (Propper, 1995).

Previous studies have analysed the responsiveness of demand to waiting times using different approaches and estimation methods. A first stream of literature uses aggregate data and takes (small) geographical areas as units of observation. Exploiting ward level information for elective surgery, Martin and Smith (2003) estimate a model where waiting times act as a price that both discourages demand and stimulates supply. Instrumental variables estimates point to a demand elasticity with respect to waiting times equal to -0.09 . Gravelle et al (2002) analyse the effect of waiting times for cataract surgery at the practice level. Cross-sectional analyses suggest that increases in waiting times have a negative and significant effect, yielding

\footnotetext{
${ }^{2}$ Accredited private hospitals generally play only a minor role (Fattore et al, 2013). In EmiliaRomagna acute care beds covered by accredited private hospitals amount to $12 \%$.
} 
an elasticity of -0.25 . Using the number of patients added to the waiting lists and the number of hospital admissions as distinct measures for demand and supply, Gravelle et al (2003) estimate panel data models on elective surgery for English Health Authorities. They find a negative association between waiting times and demand for elective care, with elasticities varying between -0.20 and -0.30 . Martin et al (2007) also use distinct measures of demand and supply based on hospital-level data. Their findings point to demand elasticities to waiting times for elective surgery ranging between -0.198 and -0.069 .

While the above studies focus on the UK, there are only very few contributions from other countries. Stavrunova et al (2011) estimate a model of the market for elective surgery using postal codes level data on Australian hospitals. The results from twostage least squares estimation indicate an elasticity of -1.7 . Using administrative data aggregated by region and by surgical procedure in Italy, Riganti et al (2017) estimate separate models of demand for and supply of elective treatments, and find a demand elasticity to waiting times ranging between -0.15 to -0.24 .

A smaller strand of literature exploits patient-level data to analyse responsiveness to waiting times, as we do in this paper. The estimation methods in hospital choice studies typically rely on the multinomial logit specification, where the dependent variable is a dummy indicator, representing the choice made by patients within a set of available alternative destinations. The use of patient-based information brings with several nice features. It helps avoid spurious results potentially arising when supplyside factors at the area level may allow to identify an effect that does not occur at the individual level (Martin and Smith, 1999). Moreover, it allows to control for 
individual patient characteristics such as geographic proximity to the hospital, thus increasing the precision in the estimates and making it possible to analyse the tradeoff between distance and waiting times (Pope, 2009). Finally, it allows to account for patient preference heterogeneity with respect to hospital characteristics.

The bulk of the literature on hospital choice uses cross-sectional data and analyses the responsiveness to hospital quality as mostly measured by clinical quality indicators, including mortality and readmission rates (e.g. Beckert et al, 2012; Varkevisser et al, 2012; Berta et al, 2016; McConnell et al, 2016). ${ }^{3}$ These studies rely on the assumption that there are no unobserved hospital characteristics affecting patient choice behaviour. To relax this assumption, other contributions use panel data, which allow to control for time-invariant unobserved heterogeneity across hospitals (e.g. Hodking, 1996; Tay, 2003; Gaynor et al, 2016; Gutacker et al, 2016).

To the best of our knowledge, Sivey (2012) is the only published work that uses individual-level panel data to specifically evaluate the impact of waiting times on hospital choice. The study examines cataract patients referred from English GP practices, and applies a multinomial logit framework where differences in quality across providers are controlled for through hospital fixed effects. The paper shows that, while the coefficient on waiting time takes a positive value before controlling for hospital time-invariant heterogeneity, it becomes negative once hospital fixed effects are included in the estimating model. In terms of magnitude, the study finds an elasticity of demand to waiting times of -0.1 .

\footnotetext{
${ }^{3}$ Brekke et al (2014) provide a comprehensive review of hospital choice studies.
} 
Given this background, we improve upon previous research that studies the effect of waiting times on hospital choice by accounting for time-invariant quality differences and time varying aspects of clinical quality at the same time. A crucial assumption underlying the attempt to control for differences in quality by means of hospital fixed effects only is that hospital quality remains stable during the period of study. However, if hospital quality changes over time and is positively correlated with waiting times, omitting to control for such feature will bias the coefficient on waiting times downward. The estimation strategy that we propose ensures a clean identification of the coefficient of interest as it disentangles the effect of waiting times from that of clinical quality. From a methodological point of view, our findings lend support to the importance of controlling for both sources of hospital heterogeneity at the same time.

\section{Methods}

The main purpose of our study is to estimate demand responsiveness to waiting times variations using patient-level data. We focus on elective PTCA surgeries, and rely on the multinomial logit framework (McFadden, 1974), where utility of patient $i$ conditional on choosing hospital $j$ at time $t$ is modelled as:

$$
U_{i j t}=V_{i j t}+v_{i j t}
$$


where $V_{i j t}$ is the deterministic component of utility and $v_{i j t}$ is the random error term. Different assumptions on the error structure and the regressors' coefficients lead to different model specifications. Our estimation procedures consist of the conditional logit (CL) and the mixed logit (ML) models. ${ }^{4}$

The CL model can be derived from the conditional utility function in (1) where the stochastic components are identically and independently distributed (iid), and follow a type- 1 extreme value distribution. Using the CL model, we specify the deterministic component of utility as:

$V_{i j t}=\beta_{d i} D_{i j}+\beta_{w i} W_{j t-1}+\beta_{s i} S_{j t-1}+\beta_{q i} Q_{j t-1}+\xi_{j}$

where $D_{i j}$ is the distance of patient $i$ from hospital $j, W_{j t-1}$ denotes the median waiting time for an elective PTCA at hospital $j$ in year $t-1, S_{j t-1}$ is the total number of elective and non-elective PTCA surgeries provided by hospital $j$ in year $t-1$, and $Q_{j t-1}$ is the quality of care at hospital $j$ in year $t-1 . \xi_{j}$ is a vector of hospitalspecific fixed effects capturing the possible influence on hospital choice of unobserved time-invariant hospital attributes. The coefficients on distance, waiting times, surgical volumes and quality of care $\left(\beta_{d i}, \beta_{w i}, \beta_{s i}\right.$ and $\left.\beta_{q i}\right)$ are allowed to vary

\footnotetext{
${ }^{4}$ The mixed logit models are also known as random-parameters, random-coefficients or errorcomponents logit (Train, 1998).
} 
with patient characteristics so as to account for variation in preferences related to observed individual characteristics. $^{5}$

Following previous studies, we assume that hospital choice responds to past, rather than current, waiting times and quality (Gutacker et al, 2016; Varkevisser et al, 2012). The use of lagged values prevents potential endogeneity due to the simultaneous influence of hospital demand on waiting times and quality. Such approach is also consistent with the view that patients gain insights into quality from previous experiences and performances.

The hospital FEs absorb potential differences between hospitals that are persistent during the sample period, and may affect patients' choice of hospital. Such differences may include, among others, teaching status, hospital size, or whether a hospital provides highly specialized services. ${ }^{6}$ The inclusion of hospital FEs is crucial for properly identifying our main effect of interest - the impact of waiting times on hospital choice. It allows to control for time-invariant hospital attributes that are unobserved to the researcher and may be correlated with waiting times. The waiting time coefficient is therefore identified by the relationship between waiting times and hospital choice within hospitals over time: a negative estimated coefficient on waiting times implies that, on average, hospitals where waiting times have increased from period $t-1$ to period $t$ have decreased demand in period $t$, ceteris paribus.

\footnotetext{
${ }^{5}$ The coefficients on distance, waiting times, surgical volumes and quality of care can be expressed as: $\beta_{d i}=\beta_{d}+X_{i}^{\prime} \delta_{d}, \beta_{w i}=\beta_{w}+X_{i}^{\prime} \delta_{w}, \beta_{s i}=\beta_{s}+X_{i}^{\prime} \delta_{s}, \beta_{q i}=\beta_{q}+X_{i}^{\prime} \delta_{q}$, where $X_{i}^{\prime}$ is a vector of observed patient characteristics.

${ }^{6}$ As noticed by previous studies, the hospital fixed effects may also absorb further (unobserved) casemix differences across hospitals (e.g. Hamilton et al, 1997).
} 
A limitation of the CL model is that it relies on the Independence from Irrelevant Alternatives (IIA) property. Under this assumption, discrimination by patients among hospitals is reduced to a series of pairwise comparisons that are unaffected by the characteristics of alternatives other than the pair under consideration, a feature that might be restrictive in this context. To overcome this limitation, we use the ML model as alternative estimation procedure.

The ML model can be derived from the conditional utility function in (1) where $v_{i j t}$ are iid extreme values. The deterministic component of utility is the same as for the CL model, except that the ML regression coefficients are allowed to vary randomly between individuals. By specifying individual-specific random coefficients, the ML model accounts for unobserved preference heterogeneity, and does not exhibit the IIA property (Revelt and Train, 1999; Train, 1998; 2003). We estimate the ML model via maximum simulated likelihood, and use 50 Halton draws for the simulation. The estimation is performed by using the econometric software Stata 14, and we apply the clogit and the mixlogit commands for the CL and the ML models, respectively (Hole, 2007).

\section{Data}

We use individual-level data for patients undergoing elective PTCA at public hospitals in the Italy's Emilia-Romagna region for the years 2008 through 2011 . $^{7}$ Our

\footnotetext{
${ }^{7}$ Located in the North East of Italy, Emilia-Romagna has a total population of nearly 4.5 million people. We use data on elective patients who reside in Emilia-Romagna. Non-elective patients are excluded from the present analysis, as they are not placed on waiting lists, given their need of immediate treatment.
} 
primary source of data is the patient discharge dataset (Schede di Dimissione Ospedaliera, SDO) that contains detailed information on each episode of discharge. Our study sample includes 15,706 patients recorded over the period 2008-2011. In any given year, the choice set is the same across all patients and embraces all publicly financed hospitals providing PTCAs in the region, among which patients can freely choose, even when they reside outside the hospital catchment area. The choice set comprises 21 public hospitals in year 2010 and 22 public hospitals in all the other years, including both ASL-run hospitals and hospital Trusts. ${ }^{8}$

The individual waiting time is measured as the difference in number of days between the date when the patient is placed on the waiting list and the date of the admission to the hospital. Consistently with choice being modelled as depending on the differences between hospital care attributes, the waiting time variable has to be computed for each hospital in the choice set. However, while the patient's actual waiting time at the chosen hospital is observed, the time that a patient would have waited had he chosen an alternative provider is unknown. To tackle this problem, we follow Sivey (2012) in using a measure of waiting times calculated at the hospital-year level as the median of the individual patients' waiting times for all elective PTCAs discharged at each hospital in each year. ${ }^{9}$

For every hospital-year pair, we calculate the volume of PTCA procedures as the total number of elective and non-elective PTCAs performed by hospitals in the year prior

\footnotetext{
${ }^{8}$ For one hospital in year 2010, there are no available information on one of our measures of hospital quality (the risk-adjusted readmission rates for AMI). Therefore, this hospital is excluded from the patients' choice set in year 2010.

${ }^{9}$ Using the median rather than the mean waits allows to account for the skewed distribution of waiting times, containing a right-hand tail of very long waits.
} 
to the admission. In this way, we control for any influence on patient's choice possibly exerted by the variation over time of hospital activity measured in terms of PTCA procedures performed.

As proxies for condition-specific hospital quality, we use the risk-adjusted mortality rates from AMI within 30 days of hospital admission and the risk-adjusted readmission rates for AMI. ${ }^{10}$ These indicators are provided at hospital-year level by the Italian Ministry of Health through the National Outcome Evaluation Program (Programma Nazionale Esiti, PNE). The PNE provides indicators for all NHS hospitals with eligible cases for selected clinical conditions and surgical interventions. Given the purpose of our analysis, we focus on the indicators related to cardiovascular treatments and available for all the years of study. Even though the PNE indicators were not disclosed to the public during the period of our analysis, we use them as proxies for hospital clinical quality as perceived by patients. Patients' perceptions of hospital quality may originate from a variety of sources, including GP and specialist advices, as well as from previous experiences formed by the patients themselves and/or by their relatives and friends (e.g. Luft et al. 1990; Moscone et al, 2012; Gutacker et al, 2016).

Travel distance is computed (in kilometres) using Microsoft MapPoint. We calculate it as the fastest road line route from the centroid of each patient's municipality of residence to each hospital site as identified by its address.

\footnotetext{
${ }^{10}$ We observe a low correlation between the risk-adjusted mortality and readmission rates, suggesting that these indicators may reflect different dimensions of hospital quality.
} 
As for patient characteristics, we include age, gender, foreign citizenship, the Charlson Comorbidity Index (CCI), and dummies for the degree of urbanization of the patient's municipality of residence. ${ }^{11}$ To account for those cases where the number of close-by destinations is very limited, we add a dummy variable taking value 1 if the patient resides in a ASL where there is only one hospital providing PTCAs, and 0 otherwise.

(Table 1 about here)

Table 1 provides summary statistics for the explanatory variables. The average hospital has a median annual waiting time equal to 16 days, provides a total of 892 PTCA treatments per year, and has risk-adjusted mortality and readmission rates equal to 9.9 and 7.5, respectively. On average, patients travel about 18 kilometres for an elective PTCA. This is about three times the average distance to the nearest hospital, suggesting that hospital choice is not uniquely driven by the purpose of minimising travel distance. Treated patients are on average 69 years old, with the share of men prevailing over women, and have on average a CCI of 1.028. Patients with foreign citizenship account for less than $2 \%$ of the total sample. Finally, the majority of patients reside in non-rural areas and have more than one hospital providing PTCA treatments in the ASL where they are enrolled.

\footnotetext{
${ }^{11}$ We use the Eurostat statistics definition to generate our dummies for the degree of urbanization of the patients' area of residence.
} 


\section{Results}

Tables 2-3 present the results obtained from the CL and the ML models. We consider four different specifications where additional sets of regressors are successively included. The most parsimonious specification (column 1) considers only distance and waiting times as drivers of hospital choice, allowing for observed preference heterogeneity through interactions with patient characteristics. We then include hospital fixed effects (column 2) and hospital volume for elective and non-elective PTCAs (column 3). In our most preferred specification illustrated in equation (2), we also add the risk-adjusted mortality and readmission rates as quality indicators (column 4).

\subsection{Conditional logit estimates}

The results from the CL model are reported in Table 2. Due to the non-linearity of the model, the coefficients can be interpreted only in terms of sign and statistical significance. In line with previous evidence, distance has a negative and highly significant effect, suggesting that on average patients prefer closer hospitals, ceteris paribus.

(Table 2 about here)

The coefficient on waiting times, which is the parameter of main interest in our analysis, is positive and significant before including any control for hospital quality (column 1). However, the impact of waiting times is no longer statistically significant 
once we account for differences across hospitals persistent over time, which are absorbed into the hospital fixed effects (column 2). While the results remain qualitatively unchanged after adding hospital surgical volume (column 3), the effect of waiting times becomes negative and highly significant when we also control for clinical quality as captured by the risk-adjusted mortality and readmission rates (column 4). This evidence calls attention to the importance of explicitly accounting for time varying quality dimensions, even after controlling for quality differences across hospitals that are fixed over time.

Columns 3 and 4 show that surgical volume has a positive and significant effect on hospital choice. However, the effect is of modest magnitude. ${ }^{12}$ As the specification reported in the last column shows, the estimated coefficients on both measures of quality are negative, implying that hospitals become more attractive when they manage to reduce mortality and readmission rates. The effect is significant at conventional significance levels for both indicators, and larger for mortality than for readmission rates.

Important insights on the factors underlying hospital choice decisions come also from the interactions between hospital attributes and patient characteristics. Our findings, reported in column 4, point to the presence of preference heterogeneity associated to observable personal characteristics. Older patients and those living in rural areas are less willing to travel, a result in line with prior research (e.g. Beckert et al, 2012). These groups appear less sensitive to variation in quality measures. Patients living in

\footnotetext{
${ }^{12}$ As hospital choice can be modelled as depending on quality, distance and waiting times only (Gaynor et al, 2016), we have also performed our analysis excluding the volume of activity of the hospital from the regressors. All the results, available upon request, are highly robust to such exclusion.
} 
rural areas are discouraged relatively less by longer waiting times compared to urban residents. Willingness to travel is higher among female patients and those with more complex conditions, with the latter group also less reluctant to wait. In addition, patients living in areas with only one hospital performing PTCAs are less willing to wait and less sensitive to differences in performance indicators. Finally, there is no evidence of observed preference heterogeneity with respect to hospital volume as the results of the interactions with patient characteristics are close to zero.

As the CL specification relies on the IIA hypothesis, we use the Hausman-McFadden test to assess the validity of the assumption in the present context. We find evidence that the IIA is not supported in our data. This restriction is relaxed by the ML model, the results of which are presented in the next sub-section.

\subsection{Mixed logit estimates}

Table 3 shows the results from the ML estimation, where the coefficient on distance is allowed to vary across patients and follows a log-normal distribution. ${ }^{13}$ All the remaining coefficients are assumed to be fixed as in the CL specification. ${ }^{14} \mathrm{We}$ estimate the ML model by maximum simulated likelihood using 50 Halton draws.

(Table 3 about here)

\footnotetext{
${ }^{13}$ The log-normal distribution ensures that each individual in the sample has a positive coefficient for the variable considered. In this study, the coefficient on distance is expected to be negative for all individuals, since travelling to more distant providers is expected to impose a welfare loss on patients, other things equal. Hence, the negative of distance is entered in estimation, so that the associated lognormally distributed coefficient is negative for every observation.

${ }^{14}$ We have also explored alternative ML specifications by allowing the coefficients on waiting times and the quality indicators to be normally and log-normally distributed. However, the results do not reveal significant preference heterogeneity for these attributes (results available upon request).
} 
The log-likelihood statistics indicate that the ML model fits the data better and provide fairly similar results to those obtained from the CL in terms of statistical significance and signs (Table 3). The estimates from our most preferred specification (column 4) show that on average patients prefer closer hospitals, shorter waiting times and higher quality as measured by lower (risk-adjusted) mortality rates. In this case, distance has a larger impact compared to the CL model. ${ }^{15}$ The coefficient on the readmission rate is also negative albeit not significant. Hospital volume of activity as measured by the total number of PTCAs performed in the year prior to the admission is positively associated with the probability that patients choose a given provider. However, in line with the CL model, the magnitude of the effect is very small.

By comparing our findings for waiting times across the ML regressions (1)-(4), we get the same indications drawn from the CL model. While the effect of waiting times on hospital choice is positive and significant before controlling for any dimension of hospital quality, it turns to be insignificant once we include hospital fixed effects, and becomes negative and significant after accounting also for time varying hospital quality. Such evidence strongly supports the proposed empirical strategy that jointly controls for both time-invariant and time varying dimensions of hospital quality. This is crucial to identify the effect of waiting times separately from the influence of relevant aspects of quality care that may be positively correlated with waiting times.

\footnotetext{
${ }^{15}$ As in our application, previous studies find that the mean coefficients in the ML model are larger than the fixed coefficients in the CL model, which implies that a large share of the variance in unobserved utility is given by the random parameters (e.g. Revelt and Train, 1998).
} 
In terms of preference heterogeneity related to observed personal characteristics, the ML provides results similar to those of the CL model. The main difference being that the ML estimates display a lower than average willingness to travel for foreign patients and for those residing in ASLs with only one hospital providing PTCAs. The ML results are suggestive of significant preference heterogeneity associated to unobserved personal characteristics. The estimated standard deviations of the distance coefficient (bottom of Table 3) are highly significant, supporting the choice of the ML over the CL model. Unobserved preference heterogeneity with respect to distance suggests that there are groups of patients who are significantly more reluctant to travel to distant providers for receiving a PTCA. ${ }^{16}$ Other studies suggest that the effect of distance may vary significantly across patients with different socioeconomic status, with those living in more income-deprived areas being more sensitive than average to distance (e.g. Beckert et al, 2012; Gutacker et al, 2016). As our analysis is based on administrative data, we do not have information on patients' socio-economic status, and our results on the distance coefficient may reflect unobserved differences in socio-economic characteristics across patients. The ML model allows to overcome this data limitation by accounting also for unobserved preference heterogeneity.

\section{Size of the effect of waiting times and quality of care on hospital choice}

We report in Table 4 a more directly interpretable quantification of the estimated effects of waiting times and clinical quality based on the results from the ML

\footnotetext{
${ }^{16}$ This finding is in line with the results provided by Varkevisser et al (2012).
} 
specification reported in column (4) of Table 3. Since we find no evidence of a significant impact of readmission rates, we focus on mortality rates as the only empirically relevant measure of clinical quality in this case.

(Table 4 about here)

Following Santos et al (2017), we estimate the demand elasticity to waiting times and quality. Precisely, we calculate the elasticity of demand of hospital $j$ with respect to own waiting times as the mean of:

$$
E_{j t}^{W_{j t-1}}=\sum_{i} P_{i j t}\left(1-P_{i j t}\right) \hat{\beta}_{w}\left(\frac{W_{j t-1}}{\sum_{i} P_{i j t}}\right)
$$

Using the same strategy, we derive the own quality demand elasticity of hospital $j$ as the average of the following equation:

$$
E_{j t}^{Q_{j t-1}}=\sum_{i} P_{i j t}\left(1-P_{i j t}\right) \hat{\beta}_{q}\left(\frac{Q_{j t-1}}{\sum_{i} P_{i j t}}\right)
$$

We find a mean waiting time elasticity equal to - 0.186 , suggesting that an increase in waiting times by 1.6 days (equivalent to $10 \%$ of the average waiting times) is associated with a decrease in demand by around 3\%. With respect to own quality, we find a mean elasticity equal to - 0.905 . This figure implies that a $1 \%$ increase in mortality rate (equivalent to $10 \%$ of the sample average mortality rate) reduces demand by around $0.9 \%$. 
To gain further insights on the size of the effect of waiting times and quality on hospital choice, we also derive the marginal rate of substitutions between waiting times, quality and travel distance. Specifically, the first row and column of Panel A gives the ratio of the marginal utility of waiting times over the marginal utility of distance for a patient with average characteristics (represented by a male aged 69 years who hold the Italian citizenship, have a CCI equal to 1.028, and reside in urban areas with multiple hospitals providing PTCAs). This ratio can be interpreted as the reference patient's willingness to travel (WTT) for shorter waiting times: it indicates the additional distance that the reference patient would be willing to travel for a reduction in waiting times by 1 day. Our estimates imply that the reference patient is willing to travel about 1.1 kilometres for a 1 week reduction in waiting times. Similarly, the second row and first column of Panel A provides our estimates of the reference patient's WTT for higher quality. We find that an average patient is willing to travel about 3.5 kilometres for being treated in a hospital that ensures a $10 \%$ reduction in the mortality rate.

In addition to the WTT for shorter waiting times and for higher quality, we examine the reference patient's trade-off between hospital waiting times and quality care, that can be referred to as willingness to wait (WTW) for better quality. As Panel B of Table 4 shows, we find that a patient with average characteristics is willing to wait about 22 days for a reduction in the hospital mortality rate by $10 \%$.

Given the highly heterogenous individual behaviour that emerges from our analysis, it is useful to provide some insights into how WTW and WTT vary with patient characteristics. For this purpose, we report in Table 5 the WTT and WTW estimates 
for different "patient-types", where relevant characteristics varies each at a time, while holding all other attributes constant at the sample mean. The exercise is performed for: females, foreigners, rural residents, and patients at the $10^{\text {th }}$ and $90^{\text {th }}$ percentiles of the age and CCI distribution.

(Table 5 about here)

Gender does not seem to have a major impact on the way patients trade-off attributes of hospital care. Women are slightly less willing than men to travel for reducing waiting times and gaining access to better performing centres. On the contrary, age differences affect both WTT and WTW for better quality. Patients at the $10^{\text {th }}$ percentile of the age distribution (55 years of age) are much more responsive to differences in outcomes across hospitals compared to patients at the $90^{\text {th }}$ percentile (89 years of age). The latter group being essentially insensitive to changes in waiting times or performance rates.

Patients at different severity levels display different WTW for better quality. Those whose CCI score equals $0\left(10^{\text {th }}\right.$ decile of the distribution $)$ are slightly less keen to wait than the average patient, while patients in more severe conditions $\left(\mathrm{CCI}=5,90^{\text {th }}\right.$ decile of the distribution) are more willing to trade-off longer waiting times for gaining access to better performing centres. Interestingly, WTT for better quality does not vary substantially across severity.

Whereas foreigners are characterised by a larger WTT for both reduced waits and increased quality compared to natives, residents in rural areas are more reluctant to 
use more distant facilities compared to urban patients. As for the WTW for better quality, foreigners come out as more keen than the average patient to wait longer in exchange for better quality, while rural residents are willing to do so relatively less.

\section{Discussion and conclusions}

Our paper estimates the demand responsiveness to changes in waiting times using patient-level data on elective PTCA surgeries in the Italian NHS. In this institutional context, where patients have free choice of hospitals and are not charged at the point of consumption, demand pressure calls for the use of non-price rationing strategies, and thus waiting times for elective procedures are expected to affect hospital choice. A major empirical challenge when estimating the elasticity of demand with respect to waiting times is the possible positive correlation between waiting times and hospital quality. To address this issue, we control for both time-invariant hospital quality (via the hospital fixed effects) and time varying aspects of hospital quality as measured by risk-adjusted mortality and readmission rates for AMI.

Using discrete choice models and exploiting the panel data structure, we document the importance of jointly accounting for time-invariant differences across hospitals as well as for time varying measures of clinical quality. Our results show that waiting times have a negative and statistically significant impact on hospital demand which is rather small in magnitude. We also highlight that patients are responsive to variations in mortality rates over time, while being less sensitive to readmission rates. Whilst the mortality rate is the most commonly used measure for the quality of clinical services, 
whether the readmission rate may also be a valid indicator of clinical outcome is debated (Romano et al, 2004). Our finding that hospital choice is significantly affected by changes in mortality rates, but not in readmission rates, supports the use of the first measure as the one that best captures a quality dimension that matters to patients.

Our analysis also finds evidence of significant preference heterogeneity in the study sample. Patient characteristics affect both the disutility from distance and the tradeoff between different hospital attributes, including waiting times and clinical quality. We find that WTT for shorter waiting times and for higher quality varies with personal characteristics. In particular, our results indicate that rural patients are less sensitive to both waiting times and quality, and we obtain very small WTT and WTW estimates for this group. Patients with higher severity are less willing to travel for shorter waiting times, and more willing to wait for higher quality. Finally, patients' responsiveness to quality significantly decreases with age, so that for older patients the estimated WTT and WTW for seeking higher quality care drop to zero. These findings bear relevant policy implications since less mobile patients are more likely to suffer when poor-quality services are delivered locally.

Previous contributions on hospital choice have studied the impact of waiting times on the demand for elective procedures exploiting individual data. However, most of them employed cross-sectional data and controlled for hospital quality using measures such as mortality and readmission rates (e.g. Beckert et al, 2012; Varkevisser et al, 2012). As far as we are aware, Sivey (2012) is the only contribution that exploits a panel data strategy to estimate the elasticity of demand to waiting times 
for hospital care. The study controls for quality differences via hospital fixed effects, thereby relying on the assumption that hospital quality is largely fixed over time. In contrast, our paper relaxes this assumption by taking advantage of a dataset that allows to disentangle the effect of waiting times from that of both time-invariant and time varying hospital quality dimensions that may be positively correlated with waiting times. Our analysis shows that omitting such factors produces downward biased estimates of the patients' responsiveness to waiting times.

The results from our most general specification come out as consistent with previous studies showing that waiting times have a small but significant negative effect on the demand for NHS inpatient care. This conveys important implications for highly regulated health care sectors. A relevant concern in such contexts is whether increasing NHS resources can be considered as a valid policy instrument to reduce the size of waiting times. However, the complex interaction between demand and supply side factors in determining waiting times suggests that increasing funding for public sector treatments may not always result in reducing waiting times effectively (e.g. Siciliani and Iversen, 2012). The key argument is that, since in NHS-type systems the price at the point of consumption is zero, increasing NHS capacity may bring forward previously latent demand. The small estimates on the elasticity of demand with respect to waiting times provided by our study suggest that the patients' response following a reduction in waiting times is likely to be relatively small. Net of this effect, increasing health care resources is expected to shorten waiting times.

Finally, our finding that hospital choice is significantly affected by changes in clinical quality suggests that increasing the scope for quality competition may have beneficial 
effects also in highly regulated settings where prices are fixed. We have shown that, even in such contexts, patients' sensitivity to quality variation makes hospitals with better health outcomes more attractive. Hence, providers have incentives to sustain quality to the extent that money follows patient decisions. At the same time, policymakers should monitor the possible consequences in terms of access to high quality care for those patients who are unlikely to bypass local providers given their personal characteristics.

\section{Acknowledgements}

We are grateful for helpful suggestions received by Arne Risa Hole, Audrey Laporte, Carol Propper, and by participants at the XXII AIES Conference in Pavia, and the Milan iHEA Congress. The research was funded by the Health Department of Emilia-Romagna (Italy), and we thank Eugenio Di Ruscio who coordinated the project for the Health Department. The views expressed are those of the authors and not necessarily those of the funders. Any errors are, of course, solely the authors' responsibility. 


\section{References}

Beckert, W., Christensen, M., Collyer, K., 2012. Choice of NHS-funded hospital services in England. The Economic Journal 122: 400-417.

Berta P., Martini G., Moscone F., Vittadini G. 2016. The association between asymmetric information, hospital competition and quality of healthcare: evidence from Italy. Journal of the Royal Statistical Society Series A, 179: 907-926.

Brekke, K., Gravelle, H., Siciliani, L., Straume, O., 2014. Patient choice, mobility and competition among health care providers. In: Levaggi, R., Montefiori, M. (Eds.), Health Care Provision and Patient Mobility. Springer.

Cookson, R., Dawson, D., 2012. Hospital competition and patient choice in publicly funded health care. In: Jones, A.M. (Eds.), Elgar Companion to Health Economics. Edward Elgar.

Culyer, A., Cullis, J., 1976. Some economics of hospital waiting lists in the NHS. Journal of Social Policy 5: 239-264.

Fattore, G., Mariotti, G., Rebba, V., 2012. "Waiting times in Italy", in Siciliani, L., Borowitz, M., Moran, V. (eds.), Waiting-time Policies in the Health Sector: What Works?, OECD Publishing, Paris.

Ferré, F., de Belvis, A.G., Valerio, L., Longhi, S., Lazzari, A., Fattore, G., Ricciardi, W., Maresso, A., 2014. Health systems in transition, Italy. WHO on behalf of the European Observatory on health care systems.

Gaynor M., Propper C., Seiler S., 2016. Free to choose? Reform, choice, and consideration sets in the English National Health Service. American Economic Review, 106: 3521-57.

Gutacker, N., Siciliani, L., Moscelli, G., Gravelle, H., 2016. Choice of hospital: which type of quality matters? Journal of Health Economics 50: 230-246.

Gravelle, H., Duscheiko, M., Sutton, M., 2002. The demand for elective surgery in a public system: Time and money prices in the UK National Health Service. Journal of Health Economics 21(3): 423-449.

Gravelle, H., Smith, P., Xavier, A., 2003. Performance signals in the public sector: The case of health care. Oxford Economic Papers 55(1): 81-103.

Gravelle, H., Siciliani, L., 2008. Ramsey waits: allocating public health service resources when there is rationing by waiting. Journal of Health Economics 27(5): 1143-1154. 
Hamilton, B.H., Hamilton, V.H., 1997. Estimating surgical volume-outcome relationships applying survival models: accounting for frailty and hospital fixed effects. Health Economics 6: 383-395.

Hodgkin, D., 1996. Specialized service offerings and patients' choice of hospital: The case of cardiac catheterization. Journal of Health Economics 15: 305-322.

Hole, A.R., 2007. Fitting mixed logit models by using maximum simulated likelihood. The Stata Journal 7 (3): 388-401.

Lindsay, C.M., Feigenbaum B., 1984. Rationing by waiting lists. American Economic Review 74: 405-417.

Luft, H.S., Garnick, D.W., Mark, D.H., Peltzman, D.J., Phibbs, C.S., Lichtenberg, E. and McPhee, S.J., 1990. Does quality influence choice of hospital? The Journal of the American Medical Association 263: 2899-2906.

Martin, S., Smith, P.C., 1999. Rationing by waiting lists: An empirical investigation. Journal of Public Economics 71: 141-164.

Martin, S., Smith, P.C., 2003. Using panel methods to model waiting times for National Health Service surgery. Journal of the Royal Statistical Society Series A, 166(Part 3): 369-387.

Martin, S., Rice, N., Jacobs, R., Smith, P.C., 2007. The market for elective surgery: Joint estimation of supply and demand. Journal of Health Economics 26: 263-285.

McConnell K.J, Lindrooth, R.C., Wholey D.R., Maddox T.M., Bloom N., 2016. Modern management practices and hospital admissions. Health Economics 25: 47085 .

McFadden, D., 1974. Conditional logit analysis of qualitative choice behaviour. In: Zarembka, P. (Ed.), Frontier in Economics, vol. 4. Academic Press, New York, pp. 105-142.

Moscone, F., Tosetti, E., Vittadini, G., 2012. Social interaction in patients' hospital choice: evidence from Italy. Journal of the Royal Statistical Society 175: 453-472.

Pope D.G., 2009. Reacting to rankings: Evidence from America's best hospitals. Journal of Health Economics 28: 1154-1165.

Propper C., 1995. The disutility of time spent on NHS waiting lists. Journal of Human Resources 30: 677-700.

Revelt, D., Train, K., 1998. Mixed logit with repeated choices: households' choices of appliance efficiency level. Review of Economics and Statistics 80: 647-657. 
Revelt, D., Train, K., 1999. Customer-specific taste parameters and mixed logit. Working Paper, University of California, Berkley.

Riganti, A., Siciliani, L., Fiorio, C.V., 2017. The effect of waiting times on demand and supply for elective surgery: Evidence from Italy. Health Economics 26(S2): $92-$ 105.

Romano, P.S., and Mutter, R., 2004. The evolving science of quality measurement for hospitals: implications for studies of competition and consolidation. International Journal of Health Care Finance and Economics 4: 131-157.

Santos, R., Gravelle, H., Propper, C., 2017. Does quality affect patients' choice of doctor? Evidence from England. The Economic Journal 127: 445-494.

Sivey, P., 2012. The effect of waiting time and distance on hospital choice for English cataract patients. Health Economics 21: 444-456.

Siciliani, L., Iversen, T., 2012. Waiting times and waiting lists. In The Elgar companion to health economics (Second ed.) chapter 24.

Stavrunova, O., Yerokhin, O., 2011. An equilibrium model of waiting times for elective surgery in NSW public hospitals. The Economic Record 87(278): 384-398.

Tay A., 2003. Assessing competition in hospital care markets: the importance of accounting for quality differentiation. Rand Journal of Economics, 34 (4): 786-814.

Train, K., 1998. Recreation demand models with taste differences over people. Land Economics 74: 230-239.

Train, K.E., 2003. Discrete Choice Methods with Simulation, $1^{\text {st }}$ ed. Cambridge University Press, Cambridge.

Varkevisser, M., van der Geest, S.A., Schut, F.T., 2012. Do patients choose hospitals with high quality ratings? Empirical evidence from the market for angioplasty in the Netherlands. Journal of Health Economics 31(2): 371-378.

Vrangbaek, K., Østergren, K., Birk, H.O., Winblad, U., 2007. Patient reaction to hospital choice in Norway, Denmark and Sweden. Health Economics, Policy and Law 2(2):125-152. 
Table 1. Descriptive statistics: years 2008-2011

\begin{tabular}{|c|c|c|}
\hline Variable & Mean & SD \\
\hline \multicolumn{3}{|l|}{ Hospital characteristics } \\
\hline Median annual inpatient waiting times & 16.184 & 9.427 \\
\hline Between-hospital variation & & 8.165 \\
\hline Within-hospital variation & & 4.890 \\
\hline Volume of all (elective and non-elective) PTCA & 892.149 & 655.165 \\
\hline Between-hospital variation & & 660.499 \\
\hline Within-hospital variation & & 83.671 \\
\hline Mortality rate from AMI & 9.891 & 2.560 \\
\hline Between-hospital variation & & 1.844 \\
\hline Within-hospital variation & & 1.798 \\
\hline Readmission rate for AMI & 7.523 & 8.300 \\
\hline Between-hospital variation & & 8.184 \\
\hline Within-hospital variation & & 1.949 \\
\hline \multicolumn{3}{|l|}{ Patient characteristics } \\
\hline Distance to hospital visited $(\mathrm{km})$ & 18.574 & 19.124 \\
\hline Distance to closest hospital $(\mathrm{km})$ & 6.424 & 6.404 \\
\hline Female & 0.263 & 0.440 \\
\hline Age & 69.024 & 11.447 \\
\hline Foreigner & 0.017 & 0.130 \\
\hline Charlson comorbidity index (CCI) & 1.028 & 1.419 \\
\hline Patient area of residence: Rural & 0.299 & 0.458 \\
\hline Semi-rural & 0.322 & 0.467 \\
\hline Urban* & 0.379 & 0.485 \\
\hline One local provider (within patient's LHA of residence) & 0.316 & 0.465 \\
\hline
\end{tabular}

\section{Sample characteristics}

No. of hospitals

No. of patients

15,706

PTCA, Percutaneous Transluminal Coronary Angioplasty. AMI, Acute Myocardial Infarction. LHA, Local Health Authority.

Notes: *omitted category in regressions. 
Table 2. Results from conditional logit estimation of hospital choice

\begin{tabular}{|c|c|c|c|c|}
\hline Independent variable & Model 1 & Model 2 & Model 3 & Model 4 \\
\hline Distance & $\begin{array}{c}-0.052 * * * \\
(0.003)\end{array}$ & $\begin{array}{c}-0.021 * * * \\
(0.003)\end{array}$ & $\begin{array}{c}-0.020 * * * \\
(0.003)\end{array}$ & $\begin{array}{c}-0.019 * * * \\
(0.003)\end{array}$ \\
\hline Waiting times & $\begin{array}{c}0.029 * * * \\
(0.007)\end{array}$ & $\begin{array}{l}-0.004 \\
(0.009)\end{array}$ & $\begin{array}{l}-0.010 \\
(0.010)\end{array}$ & $\begin{array}{c}-0.041 * * * \\
(0.011)\end{array}$ \\
\hline Volume of all PTCA & - & - & $\begin{array}{c}0.001^{* * *} * \\
(0.000)\end{array}$ & $\begin{array}{c}0.001 * * * \\
(0.000)\end{array}$ \\
\hline AMI mortality rate & - & - & - & $\begin{array}{c}-0.241 * * * \\
(0.036)\end{array}$ \\
\hline AMI readmission rate & - & - & - & $\begin{array}{c}-0.031^{*} \\
(0.016)\end{array}$ \\
\hline \multicolumn{5}{|c|}{ Interactions with distance } \\
\hline Female & $\begin{array}{c}0.010 * * * \\
(0.002)\end{array}$ & $\begin{array}{c}0.010 * * * \\
(0.002)\end{array}$ & $\begin{array}{c}0.008 * * * \\
(0.002)\end{array}$ & $\begin{array}{c}0.008 * * * \\
(0.002)\end{array}$ \\
\hline Age & $\begin{array}{c}-0.001 * * * \\
(0.000)\end{array}$ & $\begin{array}{c}-0.001 * * * \\
(0.000)\end{array}$ & $\begin{array}{c}-0.001 * * * \\
(0.000)\end{array}$ & $\begin{array}{c}-0.001 * * * \\
(0.000)\end{array}$ \\
\hline Foreigner & $\begin{array}{l}-0.001 \\
(0.005)\end{array}$ & $\begin{array}{l}-0.001 \\
(0.005)\end{array}$ & $\begin{array}{c}0.001 \\
(0.005)\end{array}$ & $\begin{array}{c}0.001 \\
(0.005)\end{array}$ \\
\hline $\mathrm{CCI}$ & $\begin{array}{c}0.004 * * * \\
(0.000)\end{array}$ & $\begin{array}{c}0.004 * * * \\
(0.001)\end{array}$ & $\begin{array}{c}0.003 * * * \\
(0.001)\end{array}$ & $\begin{array}{c}0.003 * * * \\
(0.001)\end{array}$ \\
\hline Rural & $\begin{array}{c}0.022 * * * \\
(0.002)\end{array}$ & $\begin{array}{c}-0.018 * * * \\
(0.002)\end{array}$ & $\begin{array}{c}-0.017 * * * \\
(0.002)\end{array}$ & $\begin{array}{c}-0.018 * * * \\
(0.002)\end{array}$ \\
\hline Semi-rural & $\begin{array}{c}0.030 * * * \\
(0.002)\end{array}$ & $\begin{array}{c}-0.027 * * * \\
(0.002)\end{array}$ & $\begin{array}{c}-0.028 * * * \\
(0.002)\end{array}$ & $\begin{array}{c}-0.028 * * * \\
(0.002)\end{array}$ \\
\hline One local provider & $\begin{array}{c}-0.011 * * * \\
(0.002)\end{array}$ & $\begin{array}{c}0.005^{* *} * \\
(0.002)\end{array}$ & $\begin{array}{c}0.001 \\
(0.002)\end{array}$ & $\begin{array}{c}0.000 \\
(0.002)\end{array}$ \\
\hline \multicolumn{5}{|c|}{ Interactions with waiting times } \\
\hline Female & $\begin{array}{c}0.004 \\
(0.003)\end{array}$ & $\begin{array}{c}0.008 * * \\
(0.004)\end{array}$ & $\begin{array}{c}0.006 \\
(0.004)\end{array}$ & $\begin{array}{c}0.006 \\
(0.004)\end{array}$ \\
\hline Age & $\begin{array}{l}-0.000 \\
(0.000)\end{array}$ & $\begin{array}{c}-0.000 * * * \\
(0.000)\end{array}$ & $\begin{array}{c}-0.000 * * * \\
(0.000)\end{array}$ & $\begin{array}{l}-0.000 \\
(0.000)\end{array}$ \\
\hline Foreigner & $\begin{array}{c}0.001 \\
(0.009)\end{array}$ & $\begin{array}{c}-0.006 \\
(0.012)\end{array}$ & $\begin{array}{c}0.000 \\
(0.012)\end{array}$ & $\begin{array}{l}-0.003 \\
(0.013)\end{array}$ \\
\hline $\mathrm{CCI}$ & $\begin{array}{c}0.003 * * * \\
(0.001)\end{array}$ & $\begin{array}{c}0.005^{* * *} * \\
(0.001)\end{array}$ & $\begin{array}{c}0.003 * * * \\
(0.001)\end{array}$ & $\begin{array}{c}0.003 * * \\
(0.001)\end{array}$ \\
\hline Rural & $\begin{array}{c}0.008 * * \\
(0.003)\end{array}$ & $\begin{array}{c}0.015 * * * \\
(0.005)\end{array}$ & $\begin{array}{c}0.021 * * * \\
(0.005)\end{array}$ & $\begin{array}{c}0.030 * * * \\
(0.005)\end{array}$ \\
\hline Semi-rural & $\begin{array}{c}0.030 * * * \\
(0.003)\end{array}$ & $\begin{array}{c}0.017 * * * \\
(0.005)\end{array}$ & $\begin{array}{c}0.020 * * * \\
(0.005)\end{array}$ & $\begin{array}{c}0.028 * * * \\
(0.005)\end{array}$ \\
\hline One local provider & $\begin{array}{c}-0.077 * * * \\
(0.003)\end{array}$ & $\begin{array}{c}-0.065^{* * *} * \\
(0.005)\end{array}$ & $\begin{array}{c}-0.075 * * * \\
(0.005)\end{array}$ & $\begin{array}{c}-0.057 * * * \\
(0.006)\end{array}$ \\
\hline \multicolumn{5}{|l|}{ Interactions with volume } \\
\hline Female & - & - & $\begin{array}{c}0.000 * * * \\
(0.000)\end{array}$ & $\begin{array}{c}0.000 * * * \\
(0.000)\end{array}$ \\
\hline Age & - & - & $\begin{array}{c}-0.000 * * * \\
(0.000)\end{array}$ & $\begin{array}{c}-0.000 * * * \\
(0.000)\end{array}$ \\
\hline
\end{tabular}


Table 2. (continued)

\begin{tabular}{|c|c|c|c|c|}
\hline Independent variable & Model 1 & Model 2 & Model 3 & Model 4 \\
\hline Foreigner & - & - & $\begin{array}{c}0.000 \\
(0.000)\end{array}$ & $\begin{array}{l}-0.000 \\
(0.000)\end{array}$ \\
\hline $\mathrm{CCI}$ & - & - & $\begin{array}{c}0.000 * * * \\
(0.000)\end{array}$ & $\begin{array}{c}0.000 * * * \\
(0.000)\end{array}$ \\
\hline Rural & - & - & $\begin{array}{c}-0.000 * * * \\
(0.000)\end{array}$ & $\begin{array}{c}-0.001 * * * \\
(0.000)\end{array}$ \\
\hline Semi-rural & - & - & $\begin{array}{c}-0.000 * * * \\
(0.000)\end{array}$ & $\begin{array}{c}-0.000^{* * *} \\
(0.000)\end{array}$ \\
\hline One local provider & - & - & $\begin{array}{c}0.000^{* * * *} \\
(0.000)\end{array}$ & $\begin{array}{c}0.000^{* *} \\
0.000\end{array}$ \\
\hline \multicolumn{5}{|c|}{ Interaction with AMI death rate } \\
\hline Female & - & - & - & $\begin{array}{c}0.008 \\
(0.013)\end{array}$ \\
\hline Age & - & - & - & $\begin{array}{c}0.003 * * * \\
(0.000)\end{array}$ \\
\hline Foreigner & - & - & - & $\begin{array}{l}-0.040 \\
(0.042)\end{array}$ \\
\hline $\mathrm{CCI}$ & - & - & - & $\begin{array}{c}-0.004 \\
(0.004)\end{array}$ \\
\hline Rural & - & - & - & $\begin{array}{c}0.022 \\
(0.017)\end{array}$ \\
\hline Semi-rural & - & - & - & $\begin{array}{c}0.001 \\
(0.017)\end{array}$ \\
\hline One local provider & - & - & - & $\begin{array}{c}0.087 * * * \\
(0.015)\end{array}$ \\
\hline \multicolumn{5}{|c|}{ Interaction with AMI readmission rate } \\
\hline Female & - & - & - & $\begin{array}{c}0.001 \\
(0.005)\end{array}$ \\
\hline Age & - & - & - & $\begin{array}{c}0.000 \\
(0.000)\end{array}$ \\
\hline Foreigner & - & - & - & $\begin{array}{c}0.004 \\
(0.017)\end{array}$ \\
\hline $\mathrm{CCI}$ & - & - & - & $\begin{array}{l}-0.002 \\
(0.002)\end{array}$ \\
\hline Rural & - & - & - & $\begin{array}{c}0.041^{* * * *} \\
(0.008)\end{array}$ \\
\hline Semi-rural & - & - & - & $\begin{array}{c}0.043 * * * \\
(0.008)\end{array}$ \\
\hline One local provider & - & - & - & $\begin{array}{c}0.021 * * * \\
(0.006)\end{array}$ \\
\hline Hospital FEs & $\mathrm{N}$ & $\mathrm{Y}$ & $\mathrm{Y}$ & $\mathrm{Y}$ \\
\hline Log-likelihood & $-16,646.4$ & $-12,775.66$ & $-12,683.29$ & $-12,605.821$ \\
\hline Number of observations & 341,471 & 341,471 & 341,471 & 341,471 \\
\hline
\end{tabular}

PTCA, Percutaneous Transluminal Coronary Angioplasty. AMI, Acute Myocardial Infarction.

Notes: All hospital-specific indicators are lagged by one year. Standard errors are in parentheses. *** indicates significance at $1 \% ; * *$ indicates significance at $5 \% ; *$ indicates significance at $10 \%$. 
Table 3. Results from mixed logit estimation of hospital choice

\begin{tabular}{|c|c|c|c|c|}
\hline \multirow{2}{*}{$\begin{array}{l}\text { Independent variables } \\
\text { Distance }\end{array}$} & Model 1 & Model 2 & Model 3 & Model 4 \\
\hline & $\begin{array}{c}-0.106^{* * * *} \\
(0.004)\end{array}$ & $\begin{array}{c}-0.170 * * * \\
(0.006)\end{array}$ & $\begin{array}{c}-0.176^{* * * *} \\
(0.006)\end{array}$ & $\begin{array}{c}-0.173 * * * \\
(0.006)\end{array}$ \\
\hline Waiting times & $\begin{array}{c}0.040 * * * \\
(0.008)\end{array}$ & $\begin{array}{c}0.014 \\
(0.011)\end{array}$ & $\begin{array}{c}0.006 \\
(0.012)\end{array}$ & $\begin{array}{c}-0.031 * * \\
(0.013)\end{array}$ \\
\hline Volume of all PTCA & - & - & $\begin{array}{c}0.002^{* * *} * \\
(0.000)\end{array}$ & $\begin{array}{c}0.002 * * * \\
(0.000)\end{array}$ \\
\hline AMI mortality rate & - & - & - & $\begin{array}{c}-0.268 * * * \\
(0.045)\end{array}$ \\
\hline AMI readmission rate & - & - & - & $\begin{array}{l}-0.006 \\
(0.019)\end{array}$ \\
\hline \multicolumn{5}{|l|}{ Interactions with distance } \\
\hline Female & $\begin{array}{c}-0.009 * * * \\
(0.002)\end{array}$ & $\begin{array}{c}-0.009 * * * \\
(0.002)\end{array}$ & $\begin{array}{c}-0.007 * * * \\
(0.002)\end{array}$ & $\begin{array}{c}-0.007 * * * \\
(0.002)\end{array}$ \\
\hline Age & $\begin{array}{c}0.001 * * * \\
(0.000)\end{array}$ & $\begin{array}{c}0.000 * * * \\
(0.000)\end{array}$ & $\begin{array}{c}0.000 * * * \\
(0.000)\end{array}$ & $\begin{array}{c}0.000 * * * \\
(0.000)\end{array}$ \\
\hline Foreigner & $\begin{array}{l}-0.005 \\
(0.005)\end{array}$ & $\begin{array}{c}-0.012 * * \\
(0.006)\end{array}$ & $\begin{array}{c}-0.014 * * \\
(0.006)\end{array}$ & $\begin{array}{c}-0.014^{* *} \\
(0.005)\end{array}$ \\
\hline $\mathrm{CCI}$ & $\begin{array}{c}-0.003 * * * \\
(0.001)\end{array}$ & $\begin{array}{c}-0.003 * * * \\
(0.001)\end{array}$ & $\begin{array}{c}-0.002 * * * \\
(0.001)\end{array}$ & $\begin{array}{c}-0.002 * * * \\
(0.001)\end{array}$ \\
\hline Rural & $\begin{array}{c}-0.025^{* * * *} \\
(0.002)\end{array}$ & $\begin{array}{c}0.000 \\
(0.002)\end{array}$ & $\begin{array}{l}-0.001 \\
(0.002)\end{array}$ & $\begin{array}{l}-0.001 \\
(0.002)\end{array}$ \\
\hline Semi-rural & $\begin{array}{c}-0.032 * * * \\
(0.002)\end{array}$ & $\begin{array}{c}0.006 * * \\
(0.002)\end{array}$ & $\begin{array}{c}0.007 * * * \\
(0.003)\end{array}$ & $\begin{array}{c}0.007 * * * \\
(0.003)\end{array}$ \\
\hline One local provider & $\begin{array}{c}0.008^{* * * *} \\
(0.002)\end{array}$ & $\begin{array}{c}-0.006^{* * *} \\
(0.002)\end{array}$ & $\begin{array}{c}-0.005^{* *} \\
(0.002)\end{array}$ & $\begin{array}{c}-0.005^{* *} * \\
(0.002)\end{array}$ \\
\hline \multicolumn{5}{|c|}{ Interactions with waiting times } \\
\hline Female & $\begin{array}{l}0.005^{*} \\
(0.003)\end{array}$ & $\begin{array}{c}0.011 * * * \\
(0.004)\end{array}$ & $\begin{array}{l}0.008^{*} \\
(0.004)\end{array}$ & $\begin{array}{l}0.009 * \\
(0.005)\end{array}$ \\
\hline Age & $\begin{array}{c}-0.000 * * * \\
(0.000)\end{array}$ & $\begin{array}{c}-0.001 * * * \\
(0.000)\end{array}$ & $\begin{array}{c}-0.001 * * * \\
(0.000)\end{array}$ & $\begin{array}{c}0.000 \\
(0.000)\end{array}$ \\
\hline Foreigner & $\begin{array}{l}-0.000 \\
(0.010)\end{array}$ & $\begin{array}{c}-0.010 \\
(0.015)\end{array}$ & $\begin{array}{l}-0.003 \\
(0.015)\end{array}$ & $\begin{array}{l}-0.007 \\
(0.016)\end{array}$ \\
\hline CCI & $\begin{array}{c}0.004 * * * \\
(0.001)\end{array}$ & $\begin{array}{c}0.006^{* * *} * \\
(0.001)\end{array}$ & $\begin{array}{c}0.004 * * * \\
(0.001)\end{array}$ & $\begin{array}{c}0.004 * * \\
(0.002)\end{array}$ \\
\hline Rural & $\begin{array}{l}0.010 * * * \\
(0.004)\end{array}$ & $\begin{array}{l}0.013 * * \\
(0.006)\end{array}$ & $\begin{array}{l}0.013 * * \\
(0.006)\end{array}$ & $\begin{array}{c}0.023 * * * \\
(0.006)\end{array}$ \\
\hline Semi-rural & $\begin{array}{c}0.032 * * * \\
(0.004)\end{array}$ & $\begin{array}{c}0.012 * * \\
(0.005)\end{array}$ & $\begin{array}{l}0.010^{*} \\
(0.006)\end{array}$ & $\begin{array}{c}0.015^{* *} \\
(0.006)\end{array}$ \\
\hline One local provider & $\begin{array}{c}-0.080 * * * \\
(0.003)\end{array}$ & $\begin{array}{c}-0.071 * * * \\
(0.005)\end{array}$ & $\begin{array}{c}-0.079 * * * \\
(0.006)\end{array}$ & $\begin{array}{c}-0.061 * * * \\
(0.007)\end{array}$ \\
\hline \multicolumn{5}{|l|}{ Interactions with volume } \\
\hline Female & - & - & $\begin{array}{l}0.000 * * * \\
(0.000)\end{array}$ & $\begin{array}{c}0.000 * * * \\
(0.000)\end{array}$ \\
\hline Age & - & - & $\begin{array}{c}-0.000 * * * \\
(0.000)\end{array}$ & $\begin{array}{c}-0.000 * * * \\
(0.000)\end{array}$ \\
\hline Foreigner & - & - & $\begin{array}{c}-0.000^{* *} \\
(0.000)\end{array}$ & $\begin{array}{c}-0.000 * * \\
(0.000) \\
(\text { continued })\end{array}$ \\
\hline
\end{tabular}


Table 3. (continued)

\begin{tabular}{|c|c|c|c|c|}
\hline Independent variables & Model 1 & Model 2 & Model 3 & Model 4 \\
\hline $\mathrm{CCI}$ & - & - & $\begin{array}{c}0.000 * * * \\
(0.000)\end{array}$ & $\begin{array}{c}0.000 * * * \\
(0.000)\end{array}$ \\
\hline Rural & - & - & $\begin{array}{c}-0.000 * * * \\
(0.000)\end{array}$ & $\begin{array}{c}-0.000 * * * \\
(0.000)\end{array}$ \\
\hline Semi-rural & - & - & $\begin{array}{c}0.000 \\
(0.000)\end{array}$ & $\begin{array}{c}0.000 \\
(0.000)\end{array}$ \\
\hline One local provider & - & - & $\begin{array}{c}0.000 * * * \\
(0.000)\end{array}$ & $\begin{array}{l}0.000 * \\
(0.000)\end{array}$ \\
\hline \multicolumn{5}{|c|}{ Interactions with AMI death rate } \\
\hline Female & - & - & - & $\begin{array}{c}0.014 \\
(0.016)\end{array}$ \\
\hline Age & - & - & - & $\begin{array}{c}0.003 * * * \\
(0.001)\end{array}$ \\
\hline Foreigner & - & - & - & $\begin{array}{l}-0.053 \\
(0.051)\end{array}$ \\
\hline CCI & - & - & - & $\begin{array}{c}0.001 \\
(0.005)\end{array}$ \\
\hline Rural & - & - & - & $\begin{array}{c}0.057 * * * \\
(0.020)\end{array}$ \\
\hline Semi-rural & - & - & - & $\begin{array}{c}0.022 \\
(0.020)\end{array}$ \\
\hline One local provider & - & - & - & $\begin{array}{c}0.081 * * * \\
(0.019)\end{array}$ \\
\hline \multicolumn{5}{|c|}{ Interactions with AMI readmission rate } \\
\hline Female & - & - & - & $\begin{array}{l}-0.006 \\
(0.007)\end{array}$ \\
\hline Age & - & - & - & $\begin{array}{l}0.000 * \\
(0.000)\end{array}$ \\
\hline Foreigner & - & - & - & $\begin{array}{c}0.005 \\
(0.021)\end{array}$ \\
\hline CCI & - & - & - & $\begin{array}{c}-0.004 * \\
(0.002)\end{array}$ \\
\hline Rural & - & - & - & $\begin{array}{c}0.007 \\
(0.009)\end{array}$ \\
\hline Semi-rural & - & - & - & $\begin{array}{c}0.003 \\
(0.009)\end{array}$ \\
\hline One local provider & - & - & - & $\begin{array}{c}0.024 * * * \\
(0.008)\end{array}$ \\
\hline SD of distance & $\begin{array}{c}0.060 * * * \\
(0.004)\end{array}$ & $\begin{array}{c}0.160 * * * \\
(0.011)\end{array}$ & $\begin{array}{c}0.162 * * * \\
(0.012)\end{array}$ & $\begin{array}{c}0.160 * * * \\
(0.012)\end{array}$ \\
\hline Hospital FEs & $\mathrm{N}$ & $\mathrm{Y}$ & $\mathrm{Y}$ & $\mathrm{Y}$ \\
\hline Log likelihood & $-16,424.6$ & $-12,302.8$ & $-12,198.5$ & $-12,148.7$ \\
\hline Number of observations & 341,471 & 341,471 & 341,471 & 341,471 \\
\hline
\end{tabular}

PTCA, Percutaneous Transluminal Coronary Angioplasty. AMI, Acute Myocardial Infarction.

Notes: All hospital-specific indicators are lagged by one year. The coefficient on distance is specified to be log-normally distributed. The models are estimated using Stata's mixlogit command (Hole, 2007). Standard errors are in parentheses. *** indicates significance at $1 \% ; * *$ indicates significance at $5 \%$; indicates significance at $10 \%$. 
Table 4. Quantitative effects of waiting times and clinical quality on hospital choice

\begin{tabular}{lcc}
\hline Panel A & \multicolumn{2}{c}{ Average elasticity } \\
\cline { 2 - 2 } Waiting times (days) & 0.158 & -0.186 \\
Mortality rate from AMI $(\%)$ & 0.351 & -0.905 \\
Panel B & & \\
\cline { 2 - 2 } Mortality rate from AMI $(\%)$ & \multicolumn{2}{c}{ WTW } \\
\cline { 2 - 2 }
\end{tabular}

AMI, acute myocardial infarction. WTT, willingness to travel. WTW, willingness to wait.

Notes: Results based on the mixed logit regression in column (4) of Table 3. Estimates derived for the reference patient.

Table 5. Willingness to travel and willingness to wait estimates across different patient groups

\begin{tabular}{lccccccc}
\hline & Female & Age = 55 years & Age = 89 years & Foreigner & CCI = 0 & CCI = 6 & Rural \\
\cline { 2 - 8 } WTT & & & & & & & \\
Waiting times (days) & 0.110 & 0.158 & 0.158 & 0.217 & 0.179 & 0.043 & 0.024 \\
Mortality rate from AMI (\%) & 0.280 & 0.596 & 0.000 & 0.720 & 0.353 & 0.342 & 0.018 \\
& & & & & & & \\
WTW & & & & & & & \\
Mortality rate from AMI (\%) & 2.500 & 3.800 & 0.000 & 3.323 & 1.968 & 7.800 & 0.750 \\
\hline
\end{tabular}

AMI, acute myocardial infarction. WTT, willingness to travel. WTW, willingness to wait.

Notes: Results based on the mixed logit regression in column (4) of Table 3. 


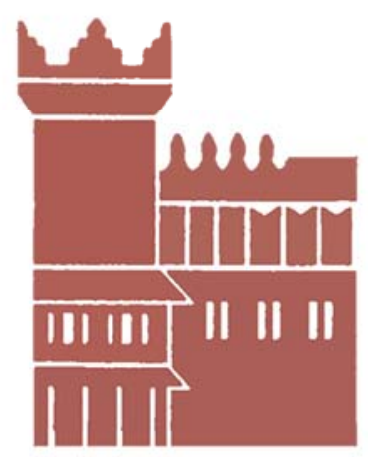

Alma Mater Studiorum - Università di Bologna DEPARTMENT OF ECONOMICS

Strada Maggiore 45

40125 Bologna - Italy

Tel. +39051 2092604

Fax +390512092664

http://www.dse.unibo.it 